\title{
WUJUD NILAI MORAL DALAM NOVEL 'SURAT KECIL UNTUK TUHAN' KARYA AGNES DAVANOR
}

\author{
Anita Bastian ${ }^{1}$ H. Rustam Efendi Rasyid ${ }^{2}$, dan Yusmah ${ }^{3}$ \\ ${ }^{1}$ MTs Ma'Had DDI Pangkajene \\ ${ }^{2,3}$ Universitas Muhammadiyah Sidenreng Rappang \\ Jl. Rusa No. 16 Pangsid Kelurahan Wala Kecamatan Maritengngae \\ anitabastian24@gmail.com
}

\begin{abstract}
Abstrak: Wujud Nilai Moral dalam Novel 'Surat Kecil untuk Tuhan' Karya Agnes Davanor. Penelitian ini merupakan kajian pragmatik yang bertujuan mendeskripsikan wujud nilai moral dalam novel 'Surat Kecil untuk Tuhan'. Data penelitian berupa tuturan pengarang dalam novel. Data dikumpulkan melalui teknik baca dan catatdan diuji validitas melalui validitas intrarater dan interrater. Data dianalisis dengan teknik deskriptif kualitatif dengan tiga tahap yaitu tahap penyediaan, analisis, dan penyajian hasil analisis data. Hasil penelitian menunjukkan bahwa wujud nilai moral yang terdapat dalam novel berupa (1) wujud nilai moral dalam hubungan manusia dengan Tuhan; (2) wujud nilai moral dalam hubungan manusia dengan diri sendiri; (3) wujud nilai moral hubungan manusia dengan manusia lain; (4) wujud nilai moral dalam hubungan manusia dengan alam.
\end{abstract}

Kata kunci: nilai moral, pragmatik, Surat Kecil untuk Tuhan

\begin{abstract}
The Form of Moral Values in the Novel 'Surat Kecil untuk Tuhan' by Agnes Davanor. This research is a pragmatic study aimed at describing the manifestation of moral values in the novel 'Surat Kecil untuk Tuhan'. Data is taken from author's speech in the novel. Data is collected through reading and recording techniques and validity is tested through intrarater and interrater validity. Data were analyzed with qualitative descriptive techniques with three stages, namely the provision, analysis and presentation of the results of data analysis. The results showed that the manifestations of moral values contained in the novel were (1) manifestations of moral values in human relations with The God; (2) manifestation of moral values in human relations with oneself; (3) the manifestation of the moral value of human relations with other humans; (4) manifestation of moral values in human relations with nature.
\end{abstract}

Keyword: moral values, pragmatic, and Surat Kecil untuk Tuhan

Karya sastra memiliki manfaat bagi pembacanya. Menurut Horace (Wellek \& Warren, 1990) fungsi karya sastra adalah dulceetutile, yang berarti indah dan bermanfaat. Keindahan yang ada dalam sastra dapat menyenangkan pembacanya, menyenangkan dalam arti dapat memberikan hiburan bagi penikmatnya dari segi bahasanya, cara penyajiannya, jalan ceritanya atau penyelesaian persoalan. Bermanfaat dalam arti karya sastra dapat diambil manfaat pengetahuan dan tidak terlepas dari ajaranajaran moralnya.
Karya sastra yang diciptakan oleh pengarang pasti mengandung nilai tertentu yang disampaikan kepada pembaca, misalnya nilai moral. Pembaca diharapkan dapat menemukan dan mengambil nilai tersebut. Kenny menyatakan bahwa moral cerita biasanya dimaksudkan sebagai suatu saran yang berhubungan dengan ajaran moral tertentu yang bersifat praktis (Nurgiyantoro, 2009). Ia merupakan petunjuk yang sengaja diberikan oleh pengarang tentang berbagai hal yang berhubungan dengan tingkah laku dan sopan santun pergaulan. 
Perkembangan teknologi informasi yang semakin pesat berpengaruh pada perilaku masyarakat. Khususnya, para remaja yang notabene lebih banyak menggunakannya. Sekarang ini perilaku para remaja semakin memprihatinkan, dalam pergaulan saat ini, remaja lebih bebas mengekspresikan diri. Bukan itu saja, remaja saat ini juga sudah minim sopan santun terhadap orang yang lebih tua. Para pelajar yang gemar melakukan tawuran, padahal tak jarang hal tersebut mereka lakukan hanya untuk mencari kesenangan saja. Seharusnya para pelajar tersebut, yang dianggap berpendidikan oleh orang-orang, dapat lebih mengerti dampak dari tawuran tersebut. Berkelahi saja merupakan tindakan tidak terpuji, apalagi berkelahi dengan memberikan banyak kerugian kepada masyarakat sekitar.

Merosotnya moral bangsa ini kembali kepada individu masing-masing. Memang tidak semua masyarakat Indonesia tidak bermoral, namun perlu kita ingat bahwa halhal tersebut membawa dampak yang sangat besar jika tidak ada perbaikan, maka dari itu harus dimulai dari diri sendiri.

Moral yang disampaikan kepada pembaca melalui karya fiksi tentunya sangat berguna dan bermanfaat. Demikian juga moral yang terdapat dalam novel Surat Kecil untuk Tuhan akan bermanfaat bagi pembaca. Novel Surat Kecil untuk Tuhan dipilih sebagai bahan penelitian karena cerita ini banyak menampilkan persoalan hidup dan kehidupan yang menarik, serta banyak terdapat nilai moral yang sangat bermanfaat bagi pembaca. Cerita remaja yang menampilkan berbagai aspek kehidupan dan permasalahanya disampaikan dengan bahasa yang menarik dan mudah dipahami. Dengan demikian akan memudahkan pembaca untuk menemukan nilai moral yang dimaksud.

\section{METODE}

Penelitian ini merupakan penelitian deskriktif kualitatif. Data penelitian berupa tuturan pengarang dalam novel. Sumber data diperoleh dari novel 'Surat Kecil Untuk Tuhan' karya Agnes Davonar yang diterbitkan oleh Inandra Published, Jakarta pada bulan Agustus 2011. Data dikumpulkan melalui teknik baca dan catat. Teknik baca dilakukan dengan membaca secara cermat setiap teks dalam novel. Teknik catat dilakukan dengan mencatat kutipan secara langsung atau disebut verbatim dari novel yang diteliti. Instrumen penelitian ini adalah peneliti sendiri dengan alat bantu kartu data. Kartu data digunakan untuk mencatat dan mentranskripsikan seluruh data yang telah diperoleh. Data dianalisis melalui teknik statistik deskriptif kualitatif yakni membandingkan antara data yang satu dengan yang lain; mengelompokan data sesuai dengan kategori yang ada untuk memudahkan analisis data selanjutnya.

\section{HASIL DAN PEMBAHASAN Hasil Penelitian}

Surat Kecil untuk Tuhan adalah sebuah buku yang diangkat dari kisah nyata perjuangan seorang gadis remaja Indonesia bernama Gita Sesa Wanda Cantika atau Keke, gadis cantik, pintar dan mantan artis penyanyi cilik berusia 13 tahun, yang menjadi penderita kanker jaringan lunak pertama kali di Indonesia. Kanker itu menyerang wajahnya yang cantik dan menjadikannya seperti monster, bahkan dokter pun mengatakan kalau hidupnya tidak akan lama lagi. Tak mau menyerah begitu saja, sang ayah terus berjuang agar Keke dapat lepas dari vonis kematian. Perjuangan sang ayah menyelamatkan putrinya begitu mengharukan, Keke yang menyadari hidupnya akan berakhir kemudian menuliskan sebuah surat kecil untuk Tuhan. Tuhan memberikan anugrah dalam hidupnya, Keke mampu bertahan bersama kanker itu selama tiga tahun lamanya walau pada akhirnya ia menyerah.

Nilai moral tokoh dalam novel ini bisa dijadikan contoh dalam kehidupan sehari-hari. Nilai moral dalam novel ini misalnya kasih sayang yang orang tua berikan kepada anak, kasih sayang orang tua ini begitu tulus. Moral merupakan sesuatu yang ingin disampaikan oleh pengarang kepada pembaca, yang merupakan makna yang terkandung dalam sebuah karya sastra dan makna yang disarankan lewat cerita (Nurgiyantoro, 2009). Jenis nilai moral itu senidiri dapat mencakup masalah, yang boleh dikatakan, bersifat dan tak terbatas. Dapat mencakup seluruh persoalan hidup dan kehidupan, seluruh persoalan yang menyangkut harkat dan 
martabat manusia. Secara garis besar persoalan hidup dan kehidupan manusia itu dapat dibedakan ke dalam persoalan hubungan manusia dengan diri sendiri, hubungan manusia dengan manusia lain dalam lingkup sosial termasuk hubungannya dengan lingkungan alam, dan hubungan manusia dengan Tuhannya (Nurgiyantoro, 2009: 323). Namun, penelitian ini menfokuskan kajian pada wujud nilai moral dalam hubungan manusia dengan Tuhannya.

Hubungan antara manusia dengan Tuhan adalah hubungan yang istimewa. Manusia sebagai makhluk tidak akan terlepas dari sang pencipta. Meski secara sadar atau tidak, semua kebutuhan manusia secara praktis akan selalu tertuju pada sang pencipta. Secara nurani hubungan manusia dengan Tuhan selalu mempunyai porsi yang lebih besar jika dibandingkan dengan makhluk lain, meski terkadang hubungan manusia dengan sang pencipta ditunjukkan dengan cara yang bermacam-macam. Baik atau buruk kelakuan manusia akan berpengaruh pada kekuatan iman terhadap Tuhan. Dalam novel Surat kecil untuk Tuhan menemukan tiga bentuk varian mengenai hubungan manusia dengan Tuhan yaitu beriman, berdoa kepada Tuhan dan sholat.

\section{Pembahasan}

Dalam novel Surat Kecil untuk Tuhan menemukan tiga bentuk varian mengenai hubungan manusia dengan Tuhan yaitu beriman, berdoa kepada Tuhan dan Sholat.

\section{1) Beriman}

Pengertian iman menurut bahasa Arab yang artinya percaya. Sedangkan menurut istilah adalah membenarkan dengan hati, diucapkan dengan lisan dan diamalkan dengan tindakan (perbuatan). Beriman kepada Allah adalah membenarkam dengan hati bahwa Allah itu benar-benar ada dengan segala sifat keagungan dan kesempurnaan-Nya, kemudian pengakuan itu diikrarkan dengan lisan serta dengan amal perbuatan secara nyata. Beriman kepada Tuhan adalah kebutuhan yang sangat mendasar bagi seseorang. Data yang ditemukan dalam novel ini tentang beriman adalah sebagai berikut.

(1) Alasanku memilih Al-Kamal tempat aku menuntut ilmu karena aku ingin mendalami Nilai agama Islam lebih dalam dan aku ingin sekali lancar membaca AlQur'an (kutipan 001).

Kutipan tersebut merupakan penyampaian nilai moral beriman. Kutipan di atas menjelaskan bahwa Keke memilih sekolah Al-Kamal karena ia ingin mendalami nilai agama Islam dan ingin lancar membaca Al-Qur'an, dan itu merupakan wujud iman Keke kepada Tuhan. Karena ayah Keke selalu mengingatkan Keke sebuah ayat dalam sebuah Hadist yaitu tentang kebaikan orang yang membaca Al-Qur'an dan mengajarkannya. Karena sesungguhnya kebahagiaan orang tua di akhirat adalah anak yang bisa membaca AlQur'an.

Berserah merupakan istilah lain dari tawakal, dalam bahasa arab yang artinya bersandar. Berserah diri kepada Tuhan setelah melakukan usaha secara maksimal adalah arti dari Tawakal. Seseorang yang berusaha secara maksimal dalam menghadapi suatu keadaan, setelah itu dia menerima dengan ikhlas dan berserah diri kepada Tuhan atas apa yang akan dia dapatkan, orang seperti itu disebut bertawakal, maka ia termasuk kedalam golongan orang yang berakhlak mulia. Berserah diri merupakan salah satu bentuk iman kepada Tuhan. Berikut merupakan kutipan data yang menunjukkan tentang moral beriman.

(2) Tuhan, aku pun berserah padamu saat ini. Dalam cobaan yang sangat berat bagiku (kutipan 002).

(3) Aku sadar kini aku mulai berserah diri kepada Tuhan untuk menjalani sisa hidupku (kutipan 003).

Kutipan data (2) dan (3) merupakan bentuk nilai moral keimanan Keke kepada Tuhan atas penyakit yang diberikan oleh Tuhan kepadanya. Dia berserah kepada Tuhan dengan apa yang telah dia alami dalam hidupnya. Sebelumnya dia telah berusaha untuk penyembuhan penyakitnya, dan sekarang ia serahkan semuanya kepada Tuhan, karena Keke percaya hanya kepada Tuhan ia dapat berserah setelah ia melakukan pengobatan semampu dia. Hal demikian merupakan bentuk iman seorang manusia kepada Tuhannya.

Kepasrahan adalah salah satu kata yang sering kali diidentikkan dengan arti menyerah. Namun di balik kata itu, sesungguhnya mempunyai arti yang luar biasa. Kepasrahan adalah sebuah kata yang seharusnya kita 
maklumi sebagai sebuah semangat untuk terus bekerja keras dan berdoa. Bentuk kepasrahan adalah salah satu bentuk keimanan manusia kepada Tuhan. Data dalam novel Surat Kecil untuk Tuhan menunjukkan sikap pasrah tokoh orang tua Keke atas penyakit yang kanker yang menimpa putrinya. Ayah Keke sudah berusaha semampunya untuk mencari pengobatan terbaik untuk putrinya itu namun penyakit yang bersarang pada tubuh anaknya masih saja ada. Tokoh ayah hanya percaya pada kebesaran Tuhan untuk putrinya itu. Kutipan data tersebut sebagai berikut.

(4) "Saya masih sulit percaya dengan ini prof. Saya hanya bisa pasrah kepada Tuhan (kutipan 004).

(5) Tubuhku terasa lemas dan aku tidak bisa melihat dengan jelas cahaya di mataku. Saat itulah aku pasrahkan semua hidupku pada Tuhan (kutipan 005).

Data nomor (5) juga merupakan bentuk nilai moral kepasrahan, yang membedakan adalah tokohnya. Pada kutipan nomor 005 menunjukkan bahwa tokoh Keke pasrah kepada Tuhan atas apa yang Tuhan berikan kepadanya termasuk penyakit kanker tersebut. Tubuh Keke sudah tidak bisa berfungsi dengan baik terutama pada bagian mata, namun dia tetap berusaha untuk tetap bisa melihat. Apapun yang Keke rasakan ia menyadari bahwa semuanya sudah ditetapkan oleh Tuhan. Ia serahkan semuanya kepada Tuhan yang telah menciptakannya. Rasa sakit yang ia derita bahkan tidak dimengerti oleh siapun kecuali dia dan Tuhan.

Davonar memperlihatkan nilai moral melalu tokoh Keke dengan menunjukkan Keke sebagai orang yang beriman. Apapun yang Tuhan berikan kepada umatnya itu adalah jalan terbaik untuk seluruh umat manusia, begitu juga dengan penyakit yang di derita oleh Keke. Keke menyadari apapun yang diberikan oleh Tuhan untuknya merupakan jalan terbaik untuk Keke dan itu merupakan rasa sayang Tuhan untuk Keke. Dari ujian yang menimpa Keke itu menjadi pelajaran untuk Keke untuk menjadi manusia yang lebih bisa bersyukur lagi dan menjadi manusia yang lebih kuat untuk menerima apapun yang Tuhan inginkan untuk Keke. Ini dapat dilihat dari kutipan berikut.
(6) Aku belajar satu hal dalam menghadapi semua ini. Kini aku siap dengan apapun yang Tuhan inginkan. Ya!! Aku akan kuat dalam menghadapi cobaan apapun

dariNya.Tuhan.... Terima kasih atas ujian terindah ini (kutipan 006).

Walaupun dalam menjalani hidup kesehatan Keke terganggu namun dia tidak pernah melewati kewajibannya sebagai seorang muslim. Dia tetap menjalani kehidupan seperti orang normal pada umumnya. Dia tidak pernah melewatkan ibadah bulan Ramadhan. Ini menunjukkanbahwa Keke adalah seorang yang beriman. Kalimat di atas dapat dilihat pada kutipan berikut.

(7) Sebentar lagi akan masuk bulan suci Ramadhan. Semua telah mempersiapkan bulan tersebut dengan baik, termasuk aku. Walaupun dalam dua tahun ini kesehatanku terganggu, aku tidak pernah melewatkan bulan tersebut (kutipan 007).

(8) Baru saja aku melewati hari idul fitri. Aku senang karena bisa melewati puasa tahun ini dengan baik. Walau sedikit bolong, setidaknya aku telah berusaha melakukan yang terbaik (kutipan 008).

Hal demikian memperlihatkan bahwa kemauan Keke untuk beriman kepada Tuhan diperlihatkan dan dijalaninya dengan baik. Keimanan manusia dapat diukur dari perbuatan yang ia lakukan. Percaya bahwa Tuhan adalah Maha Besar dan Maha Sempurna. Percaya bahwa apapun yang kita inginkan kepada Tuhan pasti akan dikabulkanNya. Contoh seperti itu yang diperlihatkan oleh Keke dalam kutipan berikut.

(9) Walaupun aku seorang pesakitan tapi aku percaya kuasa Tuhan akan membuatku mampu melewati semua ini seperti biasanya. Walaupun tanganku mulai sulit untuk bergerak tapi aku mempunyai kekuatan untuk itu (kutipan 009).

Dituliskan bahwa, dalam kutipan tersebut tokoh Keke percaya atas kuasa Tuhan. Dia percaya bahwa apapun yang tengah ia rasakan Tuhan tidak akan pernah membiarkan ia kesulitan dan akan membuatnya mampu melewati semuanya. Walaupun tangannya sulit untuk digerakkan namun ia percaya Kuasa Tuhan akan membuatnya mampu menyelesaikan ujiannya. 


\section{2) Berdoa kepada Tuhan}

Pada dasarnya seorang individu melakukan doa untuk memohon segala sesuatu yang dibutuhkan, yang diinginkan ataupun hanya untuk menenangkan diri dari segala kesusahan, namun sebenarnya doa mempunyai fungsi dan kegunaan yang tak terhingga. Doa juga merupakan salah satu alat komunikasi manusia dengan Sang Pencipta. Dapat dikatakan bahwa setiap orang yang beragama pasti berdoa. Doa menjadi bagian yang esensial dalam kehidupan manusia yang beragama akan selalu berdoa agar memperoleh keselamatan dan ketenangan. Doa merupakan peranan penting untuk kelangsungan dan perjalanan hidup manusia, untuk itu hampir disetiap perjalanan umat beragama, ia akan melakukan segala sesuatu agar ia memperoleh selamat dan sejahtera. Doa adalah permohonan kepada Tuhan. Sedangkan berdoa adalah mengucapkan doa kepada Tuhan yang disertai kerendahan hati untuk mendapatkan suatu kebaikan dan kemaslahatan yang berada di sisi-Nya. Bentuk nilai moral berdoa kepada Tuhan dapat dilihat pada kutipan data berikut.

(10) Kalau sudah begini aku hanya bisa berdoa semoga saja Tuhan mengabulkan permohonanku (kutipan 010).

(11) Aku hanya bisa berdoa kepada Allah semoga yang aku khawatirkan tidak terjadi (kutipan 011).

Kutipan data (10) dan menunjukkan bahwa tokoh aku (Keke) sangat menggantungkan dirinya kepada Sang Pencipta. Ini merupakan moral yang dapat ditiru oleh pembaca. Dia tidak pernah lupa memanjatkan doa kepada Tuhan setelah dia merasa sudah melakukan yang terbaik dalam hidupnya, karena Keke percaya bahwa apapun yang akan dia kerjakan tidak akan bisa berjalan dengan baik tanpa campur tangan Tuhan.

(12) Rasa sakit kepala atau ngilu akan kutahan. Aku percaya Tuhan akan membantuku setiap aku berdoa agar ia mengusir rasa sakit itu(kutipan 012).

Dari kutipan data (12) menjelaskan bahwa kepercayaan Keke yang begitu besar kepada Tuhan membuat ia selalu menyerahkan segala sesuatunya kepada Tuhan. Bahkan ketika ia merasakan sakit ia hanya berdoa kepada Tuhan untuk mengusir rasa sakit seperti yang sedang ia rasakan.
(13) Aku berdoa kepada Tuhan semoga tidak ada hal yang buruk pada penyakit ayah (kutipan 013).

Tokoh Keke juga sangat menyayangi orang tuanya. Dia sangat khawatir ketika mengetahui ayahnya sedang sakit dan dibawa ke rumah sakit. Ketika Keke tidak bisa berada di samping ayahnya ketika ayahnya sakit ia hanya bisa berdoa kepada Tuhan agar penyakit sang ayah segera sembuh, dan tidak terjadi hal-hal yang tidak diinginkan.

\section{3) Sholat}

Sholat merupakan ritual ibadah bagi pemeluk agama Islam. Sholat juga merupakan kewajiban yang harus dijalankan oleh setiap umat yang memeluk agama islam tanpa terkecuali baik sedang sehat maupun sakit. Sholat ialah salah satu alat komunikasi antara manusia dengan Tuhannya sebagai bentuk ibadah yang didalamnya merupakan amalan baik. Sudah dijelaskan di atas bahwa beriman kepada Tuhan adalah membenarkan dengan hati bahwa Allah itu benar-benar ada dengan segala sifat keagungan dan kesempurnaanNya, kemudian pengakuan itu diikrarkan dengan lisan serta dengan amal perbuatan secara nyata. Sholat merupakan salah satu bentuk keiman manusia kepada Tuhan. Kutipan data berikut merupakan bentuk moral keimanan Keke kepada Tuhan.

(14) Dan malam itu aku pun sholat untuk meminta petunjuk dari yang Kuasa dan bersyukur atas segala yang Tuhan berikan padaku walau dengan penyakit ini sekalipun (kutipan 014).

(15) Belum lama aku merebahkan tubuhku, adzan Magrib pun berkumandang. Langsung saja aku bangkit dari tempat tidurku dan menuju kamar mandi untuk mengambil air wudhu. Setelah aku merasa bersih, langsung saja ku ambil mukena, dilanjutkan dengan sholat, aku berdoa kepada Allah agar jalan hidupku dimudahkan. Aku berdoa pula semoga yang selama ini aku khawatirkan tidak terjadi. Semoga kanker itu tidak pernah kembali lagi padaku (kutipan 015).

Dari kutipan data (14) dan (15) dapat dijelaskan bahwa tokoh Keke adalah orang yang taat beribadah, dalam keadaan apapun dia tidak pernah meninggalkan kewajibannya, walaupun ia sedang sakit tapi ia tidak pernah meninggalkan sholat. Keke yakin bahwa Allah selalu ada untuk Keke, dan Allah lah yang akan memberikan jalan disetiap cobaan yang 
Allah berikan kesetiap umatnya. Keke juga tidak pernah lupa bahwa Allah lah yang hanya memberikan kesembuhan dan selalu memudahkan jalan yang akan dijalaninya. Apapun yang Tuhan berikan kepada Keke, dia selalu bersyukur meskipun itu sebuah penyakit. Tokoh Keke tidak pernah mengeluh.

(16) Sebelum menjalani proses kemoterapi itu, aku pun banyak melakukan doa dan sholat untuk memuluskan iman dan taqwaku kepada Tuhan (kutipan 016).

Dalam kutipan (16) di atas menjelaskan bahwa tokoh aku sangat cemas ketika akan menjalani proses kemoterapi, karena ia tidak terbiasa berada di kamar rumah sakit. Cara dia menghilangkan cemas dengan berdoa kepada Tuhan agar semua berjalan dengan lancar. Keke merupakan anak yang sangat percaya dengan kebesaran Tuhan. Keke juga termasuk

\section{DAFTAR PUSTAKA}

Damono, Supardi Djoko. 1984. Sosiologi Sastra Sebuah Pengantar Ringkas. Jakarta: Pusat Pembinaan dan Pengembangan Bahasa.

Daroesa, Bambang. 1986. Dasar dan Konsep Pendidikan Moral. Semarang: Aneka Ilmu.

Davonar, Agnes. 2011. Surat Kecil Untuk Tuhan. Jakarta: Inandra Publisher.

Departemen Pendidikan Nasional. 2008. Kamus Besar Bahasa Indonesia (KBBI), Edisi Keempat. Jakarta: Balai Pustaka.

Endraswara, Suwardi. 2004. Metodologi Penelitian Sastra. Yogyakarta: Pustaka Widyatama.

Fananie, Zainuddin. 2002. Telaah Sastra. Surakarta: Muhammadiyah Unversity Press.

Febriyanti, Andriyani Ika. 2009. Nilai-Nilai Moral Pada Cerita Pilihan Dalam Rubrik "Yunior" Surat Kabar Suara Merdeka Sebagai Alternativ Bahan PengNilai sastra. Yogyakarta: FBS. UNY.

Haricahyono, Cheppy. 1995. Dimensi-Dimensi Pendidikan Moral. Semarang: IKIP Semarang Pers.

Haryanti, Sri. 1999. Nilai-nilai Moral dalam Cerita Remaja Minggu Pagi. Yogyakarta: FBS. UNY.

Jabrohim. 2012. Teori Penelitian Sastra. Yogyakarta: Pustaka Pelajar.

Meoleong, J. Lexy. 1995. Metodology Penelitian Kualitatif. Bandung: PT. Remaja Rosdakarya. manusia yang beriman dan bertaqwa kepada Tuhan Yang Maha Esa.

\section{PENUTUP}

Wujud nilai moral dalam hubungan manusia dengan Tuhannya dalam Novel 'Surat Kecil untuk Tuhan' Karya Agnes Davonar memiliki varian yang berupa beriman, berdoa kepada Tuhan, dan sholat. Penulis menyarankan untuk dapat meneliti novel ini dengan kajian yang berbeda, misalnya dilihat dari aspek psikologi yang terdapat dalam novel Surat Kecil untuk Tuhan karya Agnes Davonar.

Nurgiyantoro, Burhan. 2009. Teori Pengkajian Fiksi. Yogyakarta: UGM.

Pradopo. Rahmat Djoko. 1995. Beberapa Teori Sastra. Metode Kritik dan Penerapan. Yogyakarta: Pustaka Pelajar.

Rasjidi, H.M. 1984. Persoalan-Persoalan Filsafat. Jakarta: Bulan Bintang.

Saryono, Djoko. 2009. Dasar Apresiasi Sastra. Yogyakarta: Elmatera Publishing.

Sayuti, Suminto A. 2000. Berkenalan dengan Prosa Fiksi. Yogyakarta: Gama Media.

Semi, Atar. 1993. Anatomi Sastra. Bandung: Angkasa Jaya.

Sudaryanto. 1993. Metode dan Aneka Teknik Analisis Bahasa. Yogyakarta: Duta Wacana University Press.

Sugihastuti. 2007. Teori dan Apresiasi Sastra. Yogyakarta: Pustaka Belajar.

Sumardjo, Jakob dan Saini K.M. 1997. Apresiasi Kesusastraan. Jakarta: Gramedia.

Tarigan, Henry Guntur. 1986. Pengajaran Pragmatik. Bandung: Angkasa.

Teeuw, A. 1984. Prinsip-prinsip Dasar Sastra. Jakarta: Pustaka Jaya.

Van Luxemburg, Jan. 1984. Pengantar Ilmu Sastra. Jakarta: Gramedia.

Wellek, Rene dan Austin Warren. 1990. Teori Kesusastraan Terjemahan Melani Budianto. Jakarta: PT Gramedia.

Wiyatmi. 2006. Pengantar Kajian Sastra. Yogyakarta: Pustaka 